\title{
AGUSTÍN ESPINOSA Y EL SIGLO DE ORO: CARTOGRAFÍAS LITERARIAS DE UN CRÍTICO
}

\author{
Carlos Brito Díaz \\ Universidad de La Laguna
}

\section{RESUMEN}

Este trabajo intenta mostrar la influencia de la tradición clásica del Siglo de Oro en la vanguardia, concretamente en la obra ensayística y creativa del polígrafo canario Agustín Espinosa García. Sus páginas sobre Góngora, Lope de Vega, Calderón y, en menor medi$\mathrm{da}$, Cervantes son un referente de la mejor prosa crítica del primer tercio del siglo $\mathrm{xx}$ en Canarias. Al margen de su atención hacia los siglos XVI y XVII, Espinosa desarrolló agudas notas sobre el Romancero, la Ilustración o la poesía francesa, entre otros muchos aspectos de su insaciable curiosidad intelectual. No fue la recuperación de Góngora en la revista $L a$ Rosa de los Vientos (en paralelo al Grupo del 27) el único proyecto de revitalización de los clásicos, regenerados e instalados en la hora de la modernidad de acuerdo a los criterios e inquietudes de la «nueva literatura» donde dialogan la tradición y vanguardia.

Palabras Clave: Agustín Espinosa, Siglo de Oro, tradición, vanguardia, «nueva literatura».

\author{
AGUSTÍN ESPINOSA AND THE GOLDEN AGE: \\ LITERARY CARTOGRAPHIES OF A CRITIC
}

\section{Abstract}

This paper tries to show the influence of the classical tradition of the Golden Age in the avant-garde, specifically in the essayistic and creative work of the Canarian writer Agustín Espinosa García. His pages on Góngora, Lope de Vega, Calderón and, to a lesser extent, Cervantes are a reference of the best critical prose of the first third of the 20th century in the Canary Islands. Apart from his attention to the sixteenth and seventeenth centuries, Espinosa developed keen notes on the Romancero, the Enlightenment or French poetry, among many other aspects of his insatiable intellectual curiosity. The recovery of Góngora in the magazine La Rosa de los Vientos (in parallel to Grupo del 27) was not the only project to revitalize the classics, regenerated and installed in the hour of modernity according to the criteria and concerns of the "new literature" where tradition and avant-garde dialogue. Keywords: Agustín Espinosa, Golden Age, tradition, avant-garde, "new literature”. 
El diálogo que los lenguajes de vanguardia establecen con el Siglo de Oro ha sido ya advertido, especialmente referido a la comentadísima celebración gongorina en el Ateneo sevillano por el Grupo del 27, que constituye uno de los capítulos más conocidos y mejor estudiados de la poesía de preguerra. También sabemos que no fue el poeta cordobés el único protagonista de la recuperación áurea, toda vez que este impulso vanguardista propició manifestaciones literarias -en gran modo metatextuales- que decantaron una interesante variedad de escritura neobarroca con otros correferentes, como Cervantes, Lope de Vega, Calderón... Este fenómeno incidió especialmente en el universo de las revistas, según han argumentado Ehrlicher y Schreckenberg (2011), en las primeras décadas del siglo xx, derivando en un crisol tanto creativo como historiográfico y crítico, que no solo visibiliza la estimación de la tradición literaria, sino "procesos de canonización» que avisan de un debate sobre la identidad cultural de la España en el umbral temprano del siglo (ibidem: 13):

Hasta ahora la investigación, en su gran mayoría, se ha limitado a analizar fenómenos del siglo xx (como la Guerra Civil, el franquismo y la Transición). Aunque esa restricción a la historia inmediata se puede entender por su impacto en la actualidad, sin embargo, para entender cómo se construye una identidad colectiva y nacional hay que tener en cuenta la historia en su longue durée. Precisamente, las luchas ideológicas a lo largo del siglo xx han demostrado que la construcción de una identidad moderna de España conllevaba también procesos de reinterpretación del Siglo de Oro como referente tradicional obligatorio.

Aurora Egido (2001) ya advierte la función que la Revista de Filología Española mostró por el Siglo de Oro como uno de sus dos ámbitos de reflexión, junto con la Edad Media, desde su primer número en 1914 bajo la guía de su fundador, Ramón Menéndez Pidal. A esta iniciativa se sumarían otras muchas en los años posteriores. No deben olvidarse tampoco -según anota Egido- los cuartos centenarios de las dos partes del Quijote, precedidos del tercer centenario de Calderón en 1881, y los tempranos trabajos gongoristas de Alfonso Reyes en la misma revista, algunos en colaboración con M.L. Guzmán, junto con los debidos al hispanismo francés. Paralelamente al restablecimiento textual y crítico del poeta cordobés circula otro que rescata a Lope de Vega en los pioneros trabajos de Américo Castro, Hugo A. Rennert y José Fernández Montesinos, «cuyo papel, como él mismo dijera en una ocasión, fue injustamente silenciado y capitalizado por los del 27» (ibidem: 28). Dicho lo cual, ha de advertirse, por tanto, una tendencia de revitalización crítica y editorial en torno al Siglo de Oro visible desde la segunda década del siglo.

En la órbita de la "nueva literatura» no debe olvidarse la conjunción de proyectos editoriales simultáneos en lo que atañe a las revistas de creación, semillero de las ideas vanguardistas y que, según se ha matizado, componen un friso mayor que el centralizador homenaje oficial del 27 a Góngora; Sánchez Robayna (1993) cita a Ramón Gómez de la Serna, atento a los impulsos renovadores, en la salutación que figura al frente de la revista canaria La Rosa de los Vientos como una contribución insular nada desdeñable al centenario gongorino; en su número 1 (abril 1927) el polígrafo madrileño apadrinaba todo esfuerzo juvenil y delataba su deseo 
de figurar "en los plácidos jardines de esas revistas» (en una nota que se publicó también en El Sol el 14 de abril), poniendo en relación la publicación tinerfeña con la malagueña Litoral, la murciana Verso y Prosa, la sevillana Mediodía, la toledana Alma y la onubense Papel de Aleluyas. Convocaba la carta que uno de los artífices de La Rosa de los Vientos, Juan Manuel Trujillo, le había enviado dándole noticia del proyecto (La Rosa de los Vientos, 1, 2003, preliminares):

Las cartas líricas de esos queridos amigos lejanos nos conmueven en la jaula del tiempo, y entonces rugimos en vano a los horizontes inalcanzables.

Por ejemplo, la carta que me escribe Juan Manuel Trujillo, que preside la futura «Rosa de los Vientos», es desgarradora y estimulante como ella sola.

"Cuando noté, un día -me dice la misiva- que de las cartas geográficas habían desaparecido las primorosas rosas de los vientos antiguas, mi alma toda se llenó de melancólicas vidrieras góticas.

Y les dije a mis amigos:

- Los cartógrafos modernos han arrancado de los mapas las rosas de los vientos. Sórdidos son los mapas desde que las rosas de los vientos no existen. Los mares azules de las cartas geográficas han perdido su inextinguible «sonrisa infinita». Uno dijo:

- La cultura de todos los países penetraba por sus picos de estrella de mar. Por eso su alma era de oro. Y los excelsos cartógrafos antiguos las pintaban con purpurina. Otro dijo:

- Sobre todo lloran su pérdida nuestras islas Canarias. Las ninfas oceánidas doliéronse de Prometeo encadenado. Nuestras islas lloran la desaparición de las rosas de los vientos.

Entonces yo dije:

-Fundemos una revista que las evoque y resucite para en adelante».

Aunque tendremos ocasión después de comentar esta revista, especialmente el número 2, de mayo de 1927, la salutación de Gómez de la Serna ilustra el espíritu ensoñador y experimental de la publicación naciente, avalado por las apostillas metafóricas de sus promotores: junto a Juan Manuel Trujillo estaban Ernesto Pestana Nóbrega, Ángel Valbuena Prat y Agustín Espinosa García; el primero citaba a sus compañeros de aventura en la carta con una visión cosmopolita e instalada en la hora contemporánea, iluminación debida, en gran modo, al último, figura señera y estimulante del surrealismo español.

Constituye, pues, la revista insular no solo una contribución más al oficialismo del 27, sino la evidencia de que la recuperación de la tradición del Siglo de Oro - por medio de la figura de Góngora, entre otros- se ejerció también desde la periferia: los jóvenes isleños adoptaron el signo de la «nueva literatura» en sincronización con las tentativas peninsulares, a pesar de lo que Gerardo Diego postulaba en su conferencia de 1961 (con motivo del tricentenario), "Góngora y la poesía moderna española»; defendía allí el signo centralizador de la "nueva literatura» en el 27 y poco más. La crítica posterior se ha encargado de desmentirlo y de mostrar la rica atomización de la actividad literaria de la vanguardia en España, en la que el caso de Canarias viene a ser una evidencia más de la particularidad creadora. Recordaba Sánchez Robayna (1998: 307) a propósito de estas reflexiones que 
no parece, pues, enfoque inadecuado (más bien todo lo contrario) singularizar crítica e historiográficamente lo que ostenta ya en sí mismo el signo de la singularidad creadora. La «estrategia» crítica mencionada de mostrar la diversidad efectiva de un panorama literario se vuelve, en verdad, ineludible cuando se trata de examinar el "caso" de Canarias. Hace ya tiempo, en efecto, que es conocido el fenómeno de la literatura de vanguardia en las Islas como un hecho que, por sus caracteres específicos y por la calidad de las obras que lo integran, merece ser destacado en un panorama que es ya en sí mismo particularmente denso en sus expresiones literarias y artísticas.

Agustín Espinosa fue, indudablemente, el mentor integral del surrealismo literario canario toda vez que en él convergen la perspectiva externa del crítico y ensayista y la condición intrínseca del creador (novelista, dramaturgo y poeta). Al margen de su actividad literaria, suficientemente estudiada, nos centraremos en un ámbito de su generoso espectro de intereses críticos, el Siglo de Oro, que convive en lúcidas reflexiones y recreaciones (no es escindible en su obra el vector creativo del vector crítico, como postula en su conocida y elocuente teoría del ensayo, definido como la simbiosis entre el «tiento» y el «análisis») con el Romancero, la Ilustración, el Romanticismo, el 98, la poesía de Ramón Feria, el cine, la «nueva literatura», las expresiones plásticas y un largo etcétera, pues nada le es ajeno en un tiempo de ebullición cultural. En un artículo en el periódico La Prensa, publicado el 3 de marzo de 1934, nuestro autor explicaba (Espinosa, 2018a: 69-70) a propósito del libro de otro compañero de la vanguardia insular, Romanticismo y cuenta nueva, de Emeterio Gutiérrez Albelo:

Hay dos maneras de hacer crítica literaria, dos modos de ver críticamente un libro, dos tratamientos que darle (algo así como el «tú» y el «usted»-penumbra o luzdel diálogo): el tiento y el análisis.

Tentar una cosa es bien distinto de analizarla. El tiento es aún emoción. El análisis es ya frialdad rígida. [...] Por vocación, se ejercita el tiento y se cultiva, por cultura, el análisis. El tiento es oficio que hay que ejercerlo de muy cerca, ciego de los dos ojos, con las manos sobre la misma masa. El análisis no puede hacerse sino desde un meditado lejos, desde una lejanía precisa, al cuidado y guarda de los ojos abiertos de par en par. A espalda de las manos trabaja el análisis y a espalda de la vista el tiento. Ambos son buenos hermanos, sin embargo. Como lo blanco y lo negro, cuando se les oye al mismo tiempo, se piensa en lo útil de su maridaje.

Espinosa conjuga ambas técnicas, cuya convivencia desarrolla una prosa donde «el análisis y el tiento se mezclan y confunden [...] y cada uno saca a flote, alternativamente, pidiéndose mutuo auxilio, los brazos. Y mientras el primero define, muequea el segundo, chilla y salta» (ibidem: 70). Esta actitud ambivalente del autor lo conduce a una revivificación de la tradición clásica desde la nueva óptica que supuso «una vivaz originalidad en los tratamientos concretos y una ruptura con los patrones de consideración crítica habituales» (Pérez Corrales, 1986, I: 35). Y en el signo de la vanguardia encontramos, de este modo, el sustrato de lo anterior, que se revelaba nueva luz en la reformulación crítica de las horas lejanas-el Romancero, 
el Siglo de Oro, la Ilustración - o cercanas -el 98, Gómez de la Serna o Juan Ramón Jiménez-. Amén de sus personales homenajes a figuras de la literatura áurea, Pérez Corrales recuerda que en 1930 Espinosa publica en Barcelona, junto con Ángel Lacalle, una Antología de escritores españoles en tres volúmenes, de los que, en el período histórico que nos ocupa, los principios del siglo XVI en el tomo I son debidos a su pluma (también se ocuparía del siglo XV en el tomo I y de los siglos XVIII y XIX en el tomo III), que despertó favorables críticas en su día por su tono «moderno».

La vanguardia fijó sus coordenadas de la modernidad proyectada hacia el pasado en aquellos autores que rompían el flujo diacrónico con el signo de la novedad y de la experimentación: de ahí las miradas a los clásicos, dentro y fuera de las Islas, que habían subvertido o que, de algún modo, admitieran una revitalización que rescatara las innovaciones que podían servir de referente y pauta a la «nueva literatura». Al respecto afirma Becerra Bolaños (2000: 89-90):

Este ideal de novedad como forma de renovación de cierto ideario estético por contraposición a la ya establecido, se plantea como prioritario, en tanto que sin esa contribución el discurso carece de fundamento. El primer momento de las vanguardias en Canarias, y más concretamente en Tenerife, viene marcado en cierta medida por esta prioridad.

Conocido es ya el tributo de la vanguardia a Góngora, y los jóvenes intelectuales canarios no irían a la zaga del 27: el poeta cordobés mereció los sagaces comentarios de Espinosa en algunos de sus textos. La visión inquieta de Juan Manuel Trujillo y sus cómplices por la aventura del cosmopolitismo y por la renovación intelectual de las Islas cristalizó en la publicación de La Rosa de los Vientos (2003, edición facsímil): solo alcanzó cinco números, de abril de 1927 a enero de 1928, y este signo de lo efímero es compartido por muchas revistas de la vanguardia ${ }^{1}$. Si el número que nos interesa es el segundo, de mayo de 1927, la publicación anticipaba en el inaugural el perfil barroquizante de un poeta conceptista del tardío Siglo de Oro: la "Antología poética de Canarias» (p. 8) consagrada al poeta canario «fray Andrés de Abreu [1647-1725], el pino y la estrella» establece un juego sugerente entre los versos del franciscano y las transfiguraciones de Espinosa y Trujillo:

[Espinosa] Su poesía -Fray Andrés de Abreu ha escrito un poema- es un grave sembrar de dentro a fuera. Con esto sigue la tradición española. Su verso es el amarillo cuerpo de la escolástica que sus anhelos requema. Y es amarillo y es rojo y es violeta.

${ }^{1}$ A propósito del carácter efímero como constante de las revistas de vanguardia, Alfonso Armas Ayala (1960: 43) comentaba: «[De La Rosa] apenas se publicaron tres, cuatro números [en rigor, cinco]. Efímera, la revista conoció igual suerte que otras peninsulares - Grecia, Ultra, Caballo Verde, Ágora, etcétera-, y, como ellas, en su fugacidad, dejó honda huella de su paso. Porque los pilotos de su singladura fueron no solo arriesgados, sino conscientes de su atrevimiento. Sabían mucho de náutica literaria, habían sabido guiar y pilotar otras naves por mares más encrespados y por eso, por la experiencia que les adornaba, se sintieron capaces del arrojo y hasta de la temeridad». 
[Trujillo] Desde su celda, él vería por un ventano cómo los hilos de plata de las estrellas se enredaban en los pinos más altos.

Por otra parte, en la sección «Feria de libros» (p. 17) Espinosa reseña la publicación de un libro de su amigo Ángel Valbuena Prat, 2+4, cuya segunda parte es una pieza alegórica, Los caminos del hombre, en la tradición del auto calderoniano, revivificado y reinstalado en la hora contemporánea:

Valbuena Prat ha resucitado a Calderón. Lo ha sacado del olvido, en que la popularidad de Lope y toda una selva de prejuicios raicificada en el setecientos lo tenía enterrado. Ha dicho: el teatro de Calderón tiene una modernidad no apreciada. En Calderón está ya Pirandello. Y nos ha hecho ver lo que no habíamos advertido: El gran teatro del mundo > Seis personajes en busca de autor. $\mathrm{Y}$ ahora trae a la literatura contemporánea una aportación nueva: la creación - con $2+4$ de una nueva tendencia, sin precedentes en la literatura contemporánea: el neocalderonismo.

Y se desmiente así la centralización del mito de la recuperación gongorina como preludio de la modernidad: antes que el poeta cordobés los vanguardistas canarios ya habían saludado la pertinencia de Calderón en la «nueva literatura». Insistirá Ángel Valbuena Prat en el número segundo, de mayo de 1927, en su celebración de los «Centenarios de viento» (p. 10):

Viendo que no corresponde a nuestro tiempo, el viento de la crítica revisa su valor, pone objeciones, señala diferencias y nos lo arrebata, hacia lejos. El vendaval es furioso, rompe los mármoles del altar y apaga la lámpara del santuario. El dios queda a oscuras, y el templo en entredicho. Ejemplo: 1881, segundo centenario de la muerte de Calderón -1681-. El viento de la crítica negativa encarna en Menéndez Pelayo. -El siglo romántico, esfumante, humanizado, tuvo que traer la vuelta a Lope. El centenario de Calderón debiera celebrarse ahora, en que el estilo -barroco, constructivo, deshumanizante- nos acerca al gran simbolista y arquitecto del teatro.

Regresemos a Góngora: junto a otros textos de Ángel Valbuena Prat (que celebra en el poeta cordobés un "Centenario de fuego»), una reseña del mismo a la edición de las Soledades de Dámaso Alonso y una «antología de D. Luis de Góngora" -en la que seguramente intervino Espinosa-, donde junto a un retablo de sonetos conviven una letrilla y un romance, el número certifica el signo del homenaje gongorino con dos textos de Espinosa: los plutárquicos («Vidas paralelas») y enfrentados «Escaparates polifémicos», un juego tipográfico y conceptual, y la nota ensayística «De Don Luis de Góngora, en el retorno de su hora poética». Nuestro poeta y crítico exhibe toda su agudeza cubista en el primero de ellos (no es casual que el número acoja una nota de Juan Rodríguez Doreste «Sobre el ángulo recto del cubismo" [p. 5], estética asociada a la técnica de descomposición de la realidad en la poesía de Góngora): un paralelismo caligramático enfrenta a dos escaparates, el clásico (Homero, Teócrito, Virgilio y Ovidio) frente al gongorino. El texto se inicia con una broma vanguardista (p. 6): 
Lector: ante tus ojos se abre una calle blanca de papel. Hay en ella dos rectangulares escaparates negros. Uno, a la izquierda. A la derecha, el otro. El primero es el de los polifemos agongorinos. El segundo, el de Polifemo de Góngora. Entra en la calle, si tienes sedes polifémicas. Yo he de atender a mis clientes.

Frente al escaparate agongorino, «vulgarizador, pequeñito, modesto», se yergue el cíclope de la Fábula, que es escaparate de esquina porque da a dos calles: es poliédrico porque en él «se ha quebrado el plano vecino», el grecolatino; sin embargo, este es «bello, armónico, germinador». De esta percepción se deduce que Espinosa no rompe con las fuentes clásicas, pues el proceso de regeneración conlleva la asunción del hipotexto toda vez que sobre este se gesta el hipertexto regenerando la secuencia mítica en su bautizada identidad atlántica: el monstruo se torna héroe y huye de su condición virgiliana para afrontar un «florecimiento deslumbrador» que engaste en la cantera de mármol (Ovidio) nuevos moldes (Góngora). El efecto del Polifemo gongorino es la descomposición violenta al modo cubista («Sobre las agudas aristas galopan sonoramente las metáforas. Fulminan los vértices») de la cosmovisión clásica, quebrada bajo la nueva iluminación sonora. El homenaje termina con una nueva humorada del crítico (p. 7):

Pero, ¡atención! Suena la zampońa -cera y cañas- del cíclope. Ha llegado el momento polifémico. Y el mío. El recuerdo ovidiano se define. Se altera el quieto mar. La selva se agita, en confusiones claras. Y Tritón rompe su bizco caracol, ya tan gastado. Y huye la vela temerosa hacia otras playas más de ella.

Que la inquietud espectadora se apague. Esto es única, espinosamente simbólico. Así es la música del fuerte Polifemo.

Ya se ha advertido la incautación crítica que se ha hecho de Góngora con respecto de su traslación cubista. Palenzuela Borges (1994: 114-115) amplía el espectro de transferencias recordando

que el proceso de apropiación moderna de Góngora se extiende desde el Modernismo hasta el peculiar vanguardismo español de los años 20, y que sigue sinuosos caminos [...]. A lo largo de este proceso se encuentran también el paso del Modernismo a las vanguardias, las comparaciones entre Góngora y Mallarmé, Góngora y el Greco, las defensas de un arte puro y, desde luego también, la importante absorción del cubismo y su vocación creacionista.

Según advierte Pérez Corrales (1986, I: 41), el cíclope había servido de inspiración para una primera versión de «Mozaga», capítulo de su Lancelot, $28^{\circ}-7^{\circ}$, editado en algunos de los fragmentos que había adelantado en la prensa. Se publicó esta visión preliminar del Polifemo convertido en atlante el 4 de junio en La Tarde, variante que Pérez Corrales incluye en su edición (1988: 105-106):

Dicen que Atlante. Bueno. Yo he creído siempre que Polifemo. Tuerto ya -ciego¡qué doloroso su caminar por la noche vasta de sus días! Relleno su pretérito de auroras de pastor solitario. Sobre todos sus pesares pesaba el gran pesar de no poder jugar a los dados. Lloró largamente sobre el cuero y el marfil inútiles. ¡Su único juguete del otońo! Empuñó el cubilete y lanzó los mil dados a los aires. 
El segundo texto del número "gongorino» goza de una excelente mirada al diagrama de la tradición gongorina: por vía del Arcipreste de Hita y del Romancero, con el enlace de Fernando de Herrera, se va gestando la tradición cultista que ofrece sus primeros brotes maduros en el Panegírico al Duque de Lerma en 1609 -también de este año son los desengañados tercetos «Mal haya el que en señores idolatra» contemplados como epístola moral (Sánchez Robayna, 1993: 83-99) - para transitar hacia la geometría poética, que se había tornado selvática sin atisbar el molde cubista en el soneto "A Guadalquivir, río de Andalucía», fechado en 1582 (Góngora, 1989: 127). La perspectiva de la relación Lope/Góngora traza aquí un tratamiento que se hace eco del maniqueísmo convencional (pato/cisne) huyendo de los estereotipos y con un tono de jocosa ironía para reducir a sus imitadores a «graznadora mesnada patil», con un haz de referencias a Juan de Valdés, Nebrija, la Celestina, Gálvez de Montalvo... Y con aguda perspicacia avisa del proceso de mimetización (in)voluntaria de los detractores («iCuántas veces se helenizarían los graves tonos del canto llano en los labios del inquieto corista! Creo que nadie hasta ahora se ha fijado en esto» [p. 12]). Y advierte la labor de desentrańamiento debida al Grupo de 1914, artífices de la "resurrección», a través de la figura de Mallarmé, tras el desdén de neoclásicos y románticos (ibidem):

Sobre el match pato-CISNE del XViI han caído tres siglos. Reciente aún el match, cígneos plumones decoraban ya el ropaje de ilustres aves españolas. El neo-clasicismo -Vd. aparte, don Juan- y el momento romántico encerraron la jaula francesa -gruesos barrotes pseudo-horacianos; vasta red de pájaros fritos sentimentales-al bello palmípedo de los andaluces giros extrańos. Hasta que una mano -la culta ganzúa novecentista- abrió - de par en par- la puerta, tantos lustros cerrada. Hoy - mayo de 1927- nuestros entusiasmos gongorinos quieren fijar sobre la obesa proa nueva del excautivo amado, la cruz farolera -mallarmiana- de esta encendida rosa de los vientos.

La visión del crítico se adelanta a gran parte de la tradición de modernos comentaristas gongorinos en un número que supuso el primer intento cohesionado de un grupo de entusiastas de/desde Canarias hacia la aventura de la contemporaneidad. Si ojeamos los números restantes comprenderemos el apetito intelectual de sus artífices y su mirada integral a la concepción de Canarias en lo universal: los poetas que editan y antologan o la interdisciplinariedad de sus páginas describen y descubren un proyecto ambicioso y cosmopolita que haría escuela:

La Rosa de los Vientos constituyó, así pues, el primer paso completo y coherente dado por la cultura hecha en Canarias dentro de la modernidad. Es cierto que su programa universal no se cumplió más que en el terreno de la ambición, y que, lejos de integrarse en las corrientes europeas, La Rosa sí vinculó a la cultura de las Islas en el panorama intelectual abierto por el novecentismo en el ámbito nacional. Se abrió así, de este modo, con lucidez y potencia, una reflexión en torno a lo insular, lo universal y lo cosmopolita que ayudó, de una manera capital, en el camino europeísta y occidental que emprendería años después Gaceta de Arte (Brito Díaz, 2003: 21).

El omphalos al frente de la revista descubre una rosa náutica bajo estética cubista que es cifra de la nueva actitud urbana con rasgos futuristas (el buque 
trasatlántico) impregnados de insularismo (la isla, la montaña -presumiblemente el Teide-, el drago, las tuneras, el agricultor, el molino) y signos de la civilización (libros, instrumento musical, papeles, partituras) en atención a los plurales intereses de la publicación, y en el punto de fuga central, la rosa de los puntos cardinales. Gómez de la Serna la transformó en greguería en el último número (enero 1928):

La rosa de los vientos parece que lo resume todo. Algo como una apariencia de síntesis, como una fantasmagoría de la síntesis parece que hay en ella. Todos los vientos y todos los colores giran. La rosa de los vientos tiende por cada una de sus puntas a una dirección distinta, se va, se alarga, vuela, vive, señala (p. 7).

Espinosa había proyectado un libro titulado Góngora y otros ensayos, donde recogería los trabajos ya analizados y una selva de textos sobre variados asuntos datables hasta 1931: solo se conserva el bosquejo inicial del proyecto con los epígrafes de sus capítulos (Espinosa, 1980: 689-690); sin embargo, como otras ocasiones, su intención no pasó de ser un esquema.

Sin embargo, no todo acaba en Góngora. Con motivo del tercer centenario de Lope en 1935 Espinosa concibe un proyecto que dejó inacabado -como otros, pues a Espinosa le faltó tiempo o disciplina para rematar sus geniales intuiciones de crítico-poeta: hay en su estilo siempre una prosa henchida de lirismo en convivencia con una sintaxis breve, sucinta, llena de cláusulas precisas, como de urgente vuelo poético y de elegante laconismo-: La Isla Arcángel, cuyo título está tomado de un verso de La Dragontea. Como avanzadilla de su granado texto lopesco Espinosa había publicado dos años antes en La Tarde el 4 de noviembre el artículo «Lope y Canarias. Un cuarto a estilos con Andrés de Lorenzo Cáceres», adelantándose a los trabajos que vendrían posteriormente acerca del ascendiente del Fénix sobre la literatura insular. El texto es un tanteo -en la concepción espinosiana- sobre el libro del amigo, aunque en parte Espinosa se desvía hacia la valoración del estilo de LorenzoCáceres. Su mirada cenital por el ensayo sobre el Fénix y las Islas surge cuando solo existían los estudios de Menéndez Pelayo sobre el tema, como bien precisa Pérez Corrales (1986, I: 45), y el crítico acierta a describir las

ocho poéticas estampas, donde se destilan las esencias de la canariedad que Los guanches de Tenerife y San Diego de Alcalá contienen, si no fuera, sobre todo, un ensayo de definición, interpretación y salvación de Canarias, hecho con la honda ternura con que Andrés de Lorenzo Cáceres cuenta siempre que, por entre sus dedos, pasa el ardiente rosario de las islas. (Espinosa, 2018: 136)

El 27 de agosto de 1935 publica en La Tarde una hermosa nota sobre el tricentenario del Fénix, "La hora de Lope», tan breve como exacta en su visión lírica sin evitar referirse - pero con elegancia- a la atribulada biografía del madrileńo (Espinosa, 2018a: 123):

Hay en la vida de Lope de Vega una hora cargada de ascetismo, hueco de bacanal, vacía de Eros, paradojal, antagónica y única: la hora de su agonía, la hora de su muerte. $[\ldots]$ 
Por esta hora pasó Lope de Vega como el acróbata del circo por el tenso aro incendiado, sintiendo sobre la piel el resquemor de su perenne llama que fue su ardiente y dinámica vida.

Pasó Lope de Vega por esta hora, llagado de cuerpo, ebrio de Dios, de sueńo extremo y nostalgias de otra nueva y sublimada existencia.

Sin duda alguna su contribución más notable al centenario lopesco fue el texto de «La Isla Arcángel de Lope», producto de una conferencia impartida el 21 de octubre en la apertura del curso 1935-1936 en el Instituto de Estudios Canarios, que no se conserva en su integridad, aunque el resumen que apareció en el diario Hoy dos días después permite reconstruir el plan general del ensayo, según precisa Pérez Corrales en la nota de su edición (Espinosa, 2018: 133). Espinosa había deslizado una mención sobre Los guanches de Tenerife a propósito de la fuente principal de la comedia, las Antigüedades de Viana, vía Menéndez Pelayo, en su «Sobre el signo de Viera", que apareció ya en 1936 pero que había adelantado en La Prensa el 2 y 3 de enero de 1932 con el título «Bajo el signo de Viera» (Pérez Corrales, 1986, I: 45). Del resumen en el diario Hoy (editado por Pérez Corrales en Espinosa, 2018: 133) sabemos que el plan original del ensayo habría incluido los epígrafes "Río», «Mar», «Puerto» y «Drake», según explica Armas Ayala (1960: 35). El poeta-crítico convierte a Lope en taumaturgo que transforma todo cuanto emprende en poesía y elogia el caudal temático con el que el Fénix conjura sus textos (geografía, mitología, historia, arte, hagiografía), al que ahora se añade el archipiélago rebautizado como islas arcángeles (aunque el verso alude a Gran Canaria). Frente a la tierra atlántica, la recia meseta castellana se perfila en el horizonte lopesco conjurado bajo el fuego, la brasa y el ardor con quienes identifica la esencia de su literatura bajo los parámetros del amor que (se) consume en la tradición petrarquista (profana) y mística (sagrada) de sus Rimas humanas (y sacras). Y proclama el aniversario de fuego -como en Góngorapara el viejo Lope, «símbolo de Espańa», en asociaciones intertextuales con Charlot, Bécquer, Poe, Larra o Baudelaire con el emblema de la vela (tiempo y consunción, pero iluminación). Frente al fuego, el agua insular de los derroteros piratas (Drake) que se desata en drama y en "prodigioso combate»:

¿Lope -ardor, fuego- busca el agua?

Va hacia ella como va la vigilia hacia el sueño. Como la vida tras la muerte. La llamaría a gritos que llenarían todo el aire de angustia, si ella misma no lo llamara ya con la ternura de una potrilla en celo. Se buscan el fuego y el agua en Lope como dos amantes en la espesura del bosque, como dos rivales dentro de un laberinto (Espinosa, 2018a: 130).

A este propósito Pérez Corrales (en Espinosa, 2018a: 133, nota del editor) arguye que

busca, por eso, Lope la frescura de los ríos, y por ellos -como en los versos de Jorge Manrique- llega hasta el mar: playa, puerto... Contrapone el Atlántico de Lope a su Mediterráneo y comprendiendo al primero como un mar espantoso, donde Lope pierde a su hermano y a su hijo, y Espańa la Invencible, como un ancho infierno sobre el que se alza de pronto la figura satanesca del pirata. Termina expo- 
niendo lo que significó, para Lope, Gran Canaria, como vencedora de Drake [con el palimpsesto de Cairasco]: «un arcángel de piedra que bajó al mismo infierno a derrotar al diablo (Drake) en su propia casa; un triunfo del catolicismo español sobre la herejía inglesa, hecho que se hace gráfico en la media luna que forman los barcos de Drake y sobre la que las balas de los castillos de Santa Ana y Santa Catalina construyen una dinámica cruz de fuego».

El agua se transforma en lágrimas, con una antítesis de signo contrario -el fuego de la pasión frente al dolor del llanto- del amor concebido como fuente de contrastes y de desorden cósmico: de este modo retoma el aire fúnebre de exequias por el centenario del Fénix. Armas Ayala dedicó un capítulo a comentar este texto, otro nuevo mito cazado que Espinosa supo entrever con agudeza y perspicacia intertextuales. Remata Armas Ayala (1960: 38-39):

Espinosa, siempre alerta, supo conjugar hábilmente las testificaciones de Cairasco y Lope; cada uno con sus versos, cada uno con su sensibilidad. Y de estos versos escogió nuestro cartógrafo la imagen feliz, cazada en lo más alto y más azul del cielo grancanario:

\section{Con unos versos y sacres}

llevados a la marina por industria de algún ángel.

Sin duda, aquel ángel que solo supo aletear para los avizores ojos de Espinosa.

En el conjunto de la recuperación de Lope como proyecto nacional con la creación incluso de una revista, Fénix. Revista del Tricentenario, también de vida efímera, se ha hablado del contexto de un neorromanticismo o neopopularismo en el seno del 27 -Lorca, Alberti-; sin embargo, frente a la gongorina, la resurrección lopesca fue diferida si tenemos en cuenta que a su redescubrimiento contribuyó decisivamente la edición de las poesías del Fénix en 1925-1926 por José Fernández Montesinos: hubo que esperar diez ańos para regresar a Lope, como muy bien advierte Díez de Revenga (2003: 143). Y antes: en el suplemento literario de La Verdad (Murcia) Juan Guerrero Ruiz había editado numerosas composiciones del Fénix desde 1924. Miguel Hernández aprendió la estructura de algún soneto en Lope, pero indudablemente el poeta más fiel a la estela del Fénix fue Gerardo Diego; recuerda Díez de Revenga (ibidem: 149) -sin duda la voz más autorizada para desbrozar la tradición áurea del lopismo en el 27- (véanse también sus otros trabajos sobre Lope en 2003):

Cuando, en 1936, Hernández publica El rayo que no cesa y García Lorca redacta sus Sonetos del amor oscuro, Gerardo Diego, uno de los más constantes y mejores sonetistas del siglo xx, está, en la misma empresa, comenzando una de sus obras maestras, Alondra de verdad, que publicaría ya después de la Guerra Civil. El libro, compuesto únicamente por cuarenta y dos sonetos, es un tributo más a Lope de Vega del más lopesco de todos los poetas del 27, el más lopesco y el más fiel, porque todavía quedarían muchos proyectos que llevar adelante al poeta de Versos humanos, y de las lopescas "Azucenas en camisa". Poemas adrede, Sonetos a Violante, Canciones a Violante, y los ensayos Una estrofa de Lope, Lope y Ramón, así como la edición de las Rimas serán obras que Diego emprenderá ya después de la guerra. 
Ya se advirtieron los entusiastas comentarios y reflexiones en La Rosa acerca de Calderón a propósito de la edición del libro de Ángel Valbuena Prat y su efusivo bautizo del neocalderonismo. Vuelve a Calderón con motivo de una fugaz visita del amigo y profesor de la Universidad de La Laguna en su ensayo «Literatura y semáforo", publicado en La Gaceta literaria, n. ${ }^{\circ}$ 65, el 1 de septiembre de 1929, donde concluye con una rotunda profesión de fe (Espinosa, 1980: 47-48):

Que no hay nada más apasionado que una aurora.

Yo creo, Valbuena Prat, que aquel retorno a Calderón que usted ya en 1927 entrañaba, va a tener en un futuro inmediato plena realización.

Yo creo en su profecía.

Yo creo en el retorno de la figura -católica, helenizante, seiscentista- de don Pedro Calderón de la Barca.

Con Cervantes y Quevedo hubo alusiones tangenciales en una nota de prensa sobre el estreno de La Edad de Oro, publicada en La Tarde el 30 de mayo de 1935. Aclara Pérez Corrales (1986, I: 46): «La asociación fundamental de Quevedo con el Espinosa surrealista viene dada por el humor negro de ambos, pero Espinosa no profundizó críticamente en ello», asociando el escándalo con el autor áureo y calificando de pacata y bizca a la crítica que tampoco transigió con Crimen, de ahí el título del texto, "Hacia una moralización de la moralina». También Quevedo aparecía citado de soslayo ańos antes en otra nota publicada el 27 de marzo de 1932 en La Provincia a propósito de los escritores que causan revuelo (Espinosa, 1980: 144): «Ni Rabelais ni Francisco Villón tienen que ver con los subvoladores. Ni han aprendido en Francia ni son alumnos de la escuela de Quevedo».

Una coda: el pretérito Siglo de Oro insular sí ocupó dos ejercicios ensayísticos -contradictorios entre sí, pero armonizados- con la visión que Espinosa desarrolló de uno de los símbolos más atractivos del pasado en el archipiélago: el de la princesa aborigen guanche Dácil a partir de su fuente original, el poema épico de Antonio de Viana Antigüedades de las Islas Afortunadas, más conocido como la Conquista de Tenerife y publicado en Sevilla en 1604 (ampliamente estudiados poema y personaje, emplazamos al lector a los trabajos de Alonso Rodríguez, recogidos en 2008: 139-323; Castells Molina, 1998; y Brito Díaz, 2000, entre otros), símbolo del mestizaje, del cosmopolitismo, de la interiorización, del sincretismo y de la insularidad, pues en su esencia está su carácter polisémico. Esta versatilidad significativa fue advertida precozmente por el primero de los «vianistas literarios», como denomina Alonso a Espinosa. El primero de los ensayos, «El Contramito de Dácil», publicado en La Prensa el 1 de septiembre de 1931, deshace el tópico de la muchacha espiando al horizonte y con el mar confidente esperando el amor que habría de llegar de tierra extraña (el del conquistador castellano Gonzalo del Castillo, historia a la que el racional Viera y Clavijo dio pábulo en su Historia de Canarias o, al menos, no desmiente), tal y como rezaba el augurio del chamán. Espinosa dinamita la imagen bucólica y eglógica (tal como la concibió Menéndez Pelayo) para metamorfosearse en una imagen de mujer moderna, burguesa y cosmopolita, alejada de las telarańas de la leyenda (Espinosa, 2017: 126): 
Hacia el mar miraba nuestra Dácil y del amor todo lo esperaba. Del mar le vino la felicidad sobre naves iberas. Llegó sobre tanta ola hasta ella, que sus manos se espumaron milagrosamente y se hicieron de vino sus ojos y se hinchó, tensa y única, la vela roja de su expectante corazón.

No mira hacia el mar la muchacha rubia. No espera del mar nada. Sino de la tierra. ¿Se ha cansado también de vuelos de gaviotas, de músicas de espuma y paradas de velas latinas?

La muchacha rubia mira hacia la tierra y solo de ella espera. Tiene una raqueta entre las manos, un suéter viste su busto y ciñen unas sandalias griegas sus pies. Para ella agitan sus ramas las acacias y se encienden las primeras estrellas. Está el mar ya tan lejos que no se ve desde las ventanas de su alcoba.

Sin embargo, Espinosa enmienda su lectura en un trabajo más desarrollado, publicado en La Prensa el 1 de mayo de 1932, con el título conciliador «La infantina de Nivaria». Matiza Alonso Rodríguez (2008: 288) que «el primer vianista literario, Agustín Espinosa [...] capta literariamente lo que él llama mito de la infantina de Nivaria, pero que me parece mejor centrar en la palabra símbolo». En esta ocasión Dácil es rosa náutica en la que convergen diferentes travesías literarias: la Nausicaa de Homero, la Minna de Walter Scott y la Elvira de Unamuno en un triángulo que traza los puntos cardinales de la mujer enamorada que se entrega al presagio de un amor lejano. Y se reconcilia con el mito (2018b: 103):

Yo, en mi "Contramito de Dácil», he querido hacer una excepción, un día. Y no había tal excepción. Era todo pura literatura. Porque la heroína de mi fábula no era nieta de Dácil, ni hija de Miss Minna, ni hermana siquiera de la señorita Elvira. Sino viajera de todos los mares. Deportiva y cosmopolita. Era más una capitana Castillo que una infantina insular, y yo la miraba con dacilianos mirares acaso.

En el triángulo equilátero de la historia literaria del mito, Homero, Scott y Unamuno, ocupan los equidistantes ángulos. Y nuestro Antonio de Viana, al centro. ¿Qué grato para nuestra lozana Infanta saber que tiene una madre griega, una nieta hispana y una hija inglesa! Que aún sigue teniendo suerte su mito. Y que mi Contramito ha sido solo un juego de un su travieso y atrabiliario bisnieto.

Palenzuela Borges ha estudiado la evolución del símbolo (1981) y Castells Molina sus variantes literarias más allá de Espinosa (1998), pues este texto motivó directamente otra iluminación del tópico, las «Cartas a Dácil» de Antonio Dorta en 1932 (Dorta, 1993).

El idilio de Espinosa con el Siglo de Oro no es más que una de las caras de su poliedro crítico: supo interpretar como nadie que el signo de la «nueva literatura» anida en la tradición, que no es más que una vanguardia en ciernes, y que la modernidad es, acaso, una tradición reinterpretada. 


\section{BIBLIOGRAFÍA}

Alonso Rodríguez, María Rosa (2008): «Antonio de Viana», en Todos los que están fueron, I. Artículos biobibliográficos 1930-2002, Islas Canarias: Consejería de Educación, Universidades, Cultura y Deportes-Excmo. Ayuntamiento de San Cristóbal de La Laguna, 179-323.

Armas Ayala, Alfonso (1960): Espinosa, cazador de mitos, Puerto de la Cruz (Tenerife): Instituto de Estudios Hispánicos.

Becerra Bolaños, Antonio (2000): «Apuntes para una teoría de la tradición en la vanguardia europea», en Antonio Becerra Bolaños y Domingo Hernández Agis (coords.), La cultura vanguardista en Canarias. Reflexiones sobre la obra de Agustín Espinosa, Granada: Proyecto Sur de Ediciones.

Brito Díaz, Carlos (2000): «Antonio de Viana», en Rafael Fernández Hernández (coord.), Historia critica de la literatura canaria, I: de los inicios al siglo XVII, Las Palmas de Gran Canaria: Ediciones del Cabildo de Gran Canaria, 387-406.

BRito DíAz, Carlos (2003): «El cíclope aprende a nadar: la hora de los clásicos españoles en La Rosa de los Vientos", en Estudios, manifiestos e indices, cuaderno complementario de La Rosa de los Vientos, ed. facsímil, Santa Cruz de Tenerife: Servicio de Publicaciones de la Caja General de Ahorros de Canarias, 23-30.

Castells Molina, Isabel (1998): "Dácil y Castillo», en AA. VV., Tópicos y argumentos en la literatura de Canarias, Gran Canaria: Dirección General de Orientación e Innovación Educativa de la Consejería de Educación, Cultura y Deportes del Gobierno de Canarias, 199-291.

Díez de Revenga, Francisco Javier (2003): «El “descubrimiento” de la poesía de Lope», en La tradición áurea. Sobre la recepción del Siglo de Oro en poetas contemporáneos, Madrid: Biblioteca Nueva, 141-149.

Dorta, Antonio (1993): Cartas a Dácil y otros ensayos, introducción, selección y notas de Isabel Castells, La Laguna: Instituto de Estudios Canarios.

Egrdo, Aurora (2001): «El Barroco en el laboratorio de las revistas (1914-1930)», en Hanno Ehrlicher y Stefan Schreckenberg (eds.), El Siglo de Oro en la España contemporánea, Madrid/ Frankfurt: Ibeoroamericana/Vervuert, 23-51.

Ehrlicher, Hanno y Stefan Schreckenberg (2011): «Introducción», en Hanno Ehrlicher y Stefan Schreckenberg (eds.), El Siglo de Oro en la España contemporánea, Madrid/Frankfurt: Ibeoroamericana/Vervuert, 7-19.

EspinosA, Agustín (1980): Textos (1927-1936), edición de Alfonso Armas Ayala y Miguel Pérez Corrales, Santa Cruz de Tenerife: Aula de Cultura.

Espinosa, Agustín (1988): Lancelot, $28^{\circ}-7^{\circ}$ [Guía integral de una isla atlántica], edición de Nilo Palenzuela, Santa Cruz de Tenerife: Editorial Interinsular Canaria.

Espinosa, Agustín (2017): Oda a María Ana, primer premio de axilas sin depilar de 1930. Textos 19301931, edición de Miguel Pérez Corrales, Tenerife: Insoladas.

Espinosa, Agustín (2018a): Crimen. Textos 1934-1936. Textos complementarios, edición de Miguel Pérez Corrales, Tenerife: Insoladas.

Espinosa, Agustín (2018b): Media hora jugando a los dados. Textos 1932-1933, edición de Miguel Pérez Corrales, Tenerife: Insoladas.

Góngora, Luis de (1989): Sonetos completos, edición de Biruté Ciplijauskaité, Madrid: Castalia. 
Palenzuela Borges, Nilo (1981): «Dácil y la tradición», Colección LC Ensayo, agosto-septiembre, 14-17.

Palenzuela Borges, Nilo (1994): «Cubismo y neogongorismo en las poéticas narrativas de los años 20", FGL. Boletín de la Fundación Federico García Lorca, 16, 113-127.

Pérez Corrales, Miguel (1986): Agustín Espinosa, entre el mito y el sueño, I, Las Palmas de Gran Canaria: Ediciones del Cabildo de Gran Canaria.

ROSA DE LOS VIENTOS, LA (2003): edición facsímil con cuaderno complementario Estudios, manifiestos e indices, Alejandro Krawietz (introducc.), Santa Cruz de Tenerife: Servicio de Publicaciones de la Caja General de Ahorros de Canarias.

SÁnchez Robayna, Andrés (1993): «Los tercetos gongorinos de 1609 como epístola moral»y "Algunos aspectos desconocidos de la conmemoración gongorina de 1927», en Silva gongorina, Madrid: Cátedra, 83-99 y 161-168, respectivamente.

SÁnchez Robayna, Andrés (1998): «La literatura de vanguardia en Canarias (1920-1939): hacia un balance crítico", en Javier Pérez Bazo (ed.), La vanguardia en España. Arte y literatura, París: Éditions du CIRC (Centre de Recherches sur la péninsule Ibérique à l'époque Contemporaine, Université de Toulouse-Le Mirail)-Ophrys, 305-327. 
